\title{
EKSPERIMEN PEMBUATAN SISTEM PENGANALISIS UNSUR DENGAN METODE GAMA SERENTAK MENGGUNAKAN SUMBER NEUTRON Pu-Be
}

\author{
Syarip \\ Pusat Penelitian dan Pengembangan Teknologi Maju
}

\begin{abstract}
ABSTRAK
EKSPERIMEN PEMBUATAN SISTEM PENGANALISIS UNSUR DENGAN METODE GAMA SERENTAK MENGGUNAKAN SUMBER NEUTRON Pu-Be. Telah dilakukan eksperimen dalam rangka pembuatan sistem penganalisis unsur-unsur dengan metode analisis aktivasi neutron gama serentak atau promt gamma neutron activation analysis (PGNAA). Tujuan eksperimen ini adalah untuk mengembangkan metode analisis aktivasi neutron sehingga dapat digunakan untuk mendeteksi unsurunsur yang memiliki waktu paroh sangat pendek. Eksperimen dilakukan dengan susunan alat yang terdiri dari : sumber neutron isotopik PuBe, detektor gama HPGe, kolimator neutron dari grafit, jarak cuplikan dengan sumber neutron $20 \mathrm{~cm}$. Pengujian dan kalibrasi sistem dilakukan dengan menggunakan sumber standar $\mathrm{Co}^{60}$ dan $\mathrm{Cs}^{137}$. Hasil eksperimen menunjukkan bahwa pengukuran fluks neutron pada target cuplikan dengan menggunakan foil $\mathrm{Au}^{198}$ menghasilkan fluks neutron rerata $3,26.10^{4} \mathrm{n} \mathrm{cm}^{-2} \mathrm{~s}^{-1}$. Sedangkan nilai resolusi dan efisiensi sistem PGNAA tersebut masing-masing adalah 5,6 \% dan 0,66 \%. Uji coba sistem dengan cuplikan berupa foil $\mathrm{Ag}^{108}$ menunjukkan hasil sesuai yang diharapkan.
\end{abstract}

\begin{abstract}
EXPERIMENT FOR CONSTRUCTION OF ELEMENTAL ANALYSIS SISTEM WITH PROMPT GAMMA METHOD USING Pu-Be NEUTRON SOURCE. The experiment in relation to the construction of elemental analysis system by the method of prompt gamma ray neutron activation analysis (PGNAA) have been done. The purpose of this experiment is to develop the neutron activation analysis method in such that it can be used to detect elements having very short half life. The experiment was done using the configuration consisted of : isotopic neutron source of Pu Be, HPGe gamma detector, neutron collimator made from graphite, with the distance between sample and neutron source of $20 \mathrm{~cm}$. Test and calibration of the system is done by using standard source $\mathrm{Co}^{60}$ and $\mathrm{Cs}^{137}$. The experiment results shows that the average neutron flux at the target/sample location measured by using Au $1^{98}$ foil detector is $3,26.10^{4} \mathrm{ncm}^{-}$ ${ }^{2} \mathrm{~s}^{-1}$. While, the resolution and efficiency of this PGNAA system was measured as 5,6\% dan 0,66\% respectively. The system was tried to be used for $\mathrm{Ag}^{108}$ measurement and shows a result as expected.
\end{abstract}

\section{PENDAHULUAN}

Demanfaatan teknik nuklir dalam berbagai bidang ilmu, seperti fisika, kimia, biologi, dan pertanian telah menunjukkan peningkatan yang cukup pesat. Salah satu pemanfaatan tersebut adalah untuk keperluan analisis unsur-unsur kelumit (trace element : yaitu unsur dalam kadar yang sangat rendah). Salah satu metode yang biasa dipakai adalah metode analisis aktivasi neutron (AAN).Dalam kehidupan di bumi ozon berguna untuk melindungi mahkluk hidup dari radiasi ultra violet yang dipancarkan sinar matahari dimana radiasi ultra violet tersebut mempunyai panjang gelombang pendek namun mempunyai energi yang sangat tinggi.

AAN adalah suatu metode analisis unsur berdasarkan radioaktivitas imbas jika suatu cuplikan diiradiasi dengan menggunakan neutron. Teknik AAN mampu mengidentifikasi unsur kelumit dalam orde bagian per juta (ppm), bahkan untuk beberapa kasus mampu hingga orde bagian 
per milyar (ppb). Di samping itu, teknik AAN tidak terpengaruh oleh perlakuan kimia dan tidak merusak terhadap bahan yang dianalisis. Dengan teknik AAN dimungkinkan analisis terhadap sekitar 50 jenis unsur yang berbeda dalam satu cuplikan secara simultan.

Kelemahan teknik AAN ini adalah tidak dapat membedakan berapa valensi unsur yang terdeteksi. Jadi, kadar yang ditentukan merupakan kadar total suatu unsur, misalnya ferri atau ferro, merkuri atau merkuro ${ }^{[1]}$. Selain itu, berdasarkan beberapa hasil penelitian yang sudah ada menunjukkan bahwa unsur yang berhasil dideteksi oleh teknik AAN ini adalah unsurunsur yang mempunyai waktu paruh panjang. Sedangkan untuk unsur-unsur yang mempunyai waktu paruh pendek (dalam orde menit atau detik) sulit dianalisis oleh teknik ini karena unsur tersebut akan meluruh terlebih dahulu sebelum berhasil dideteksi. Hal ini karena teknik AAN memerlukan waktu yang tidak sedikit untuk proses pencacahan cuplikan sampai analisisnya.

Oleh karena itu, perlu dikembangkan teknik pencacahan gamma secara langsung tanpa adanya pemindahan cuplikan dari medan neutron sehingga dapat mendeteksi unsur-unsur yang mempunyai waktu paruh pendek. Metode ini disebut metode aktivasi neutron gamma serentak (PGNAA = Prompt Gamma Neutron Activation Analysis). Metode ini mampu mendeteksi radiasi gamma yang dipancarkan oleh suatu atom langsung dalam selang waktu $10-15$ $\operatorname{detik}^{[2]}$

Tujuan dari eksperimen dalam penelitian ini adalah untuk : membuat susunan lengkap sistem analisis unsurunsur dengan metode aktivasi neutron gamma serentak beserta kalibrasinya. Selain itu juga untuk mengembangkan teknik AAN sehingga dapat digunakan untuk mendeteksi unsur-unsur yang mempunyai waktu paruh yang sangat pendek.

\section{PRINSIP DASAR METODE AAN}

\section{Analisis Aktivasi Neutron (AAN)}

Prinsip dasar AAN adalah timbulnya radioaktivitas imbas dari suatu cuplikan setelah diiradiasi oleh neutron. Cuplikan yang akan dianalisis, diiradiasi dengan menggunakan suatu sumber neutron maka terjadi reaksi penangkapan neutron oleh inti atom unsur-unsur tersebut dan berubah menjadi radioaktif. Reaksi ini disebut reaksi pengaktifan neutron, yang biasa ditulis sebagai reaksi neutron-gamma (n, $\gamma)$. Secara umum reaksinya dapat dituliskan sebagai berikut :

${ }_{\mathrm{z}} \mathrm{X}^{\mathrm{A}}+{ }_{0} \mathrm{n}^{1} \rightarrow{ }_{\mathrm{z}} \mathrm{X}^{\mathrm{A}+1}+\gamma$

dengan : A dan $\mathrm{Z}$ masing-masing adalah nomor atom dan nomor massa dari unsur $\mathrm{X}$. Hasil reaksi di atas adalah isotop yang bersifat radioaktif yang memancarkan sinar gamma yang dipancarkan oleh berbagai unsur dalam cuplikan. Intensitas sinar gamma spesifik tersebut sebanding dengan jumlah isotop dalam cuplikan. Analisis kualitatif dilakukan berdasarkan penentuan tenaga sinar gamma, sedang analisis kuantitatif dilakukan dengan menentukan intensitasnya

Kelemahan teknik AAN terletak pada keterbatasannya mendeteksi unsur-unsur yang mempunyai waktu paruh pendek. Umumnya unsur tersebut akan meluruh terlebih dahulu sebelum berhasil dianalisis.

\section{Analisis Aktivasi Neutron Gamma Serentak (PGNAA)}

Berdasarkan pada waktu pengukuran emisi gammanya, teknik AAN dapat dibedakan menjadi 2 bagian yaitu :

1. Metode analisis aktivasi neutron gamma peluruhan (DGNAA = Delayed Gamma Neutron Activation Analysis), di mana waktu pengukurannya beberapa saat 
setelah proses iradiasi atau setelah bahan radioaktif meluruh.

2. Metode analisis aktivasi neutron gamma serentak (PGNAA = Prompt Gamma Neutron Activation Analysis), di mana waktu pengukurannya langsung pada saat atau selama proses iradiasi.

Dari kedua jenis pengukuran tersebut, teknik AAN secara umum lebih dikenal dalam jenis pengukuran yang sama dengan teknik DGNAA, karena teknik AAN mencacah gamma hasil peluruhan unsur radioaktif.

Teknik PGNAA secara umum dilakukan dengan menggunakan berkas neutron yang berasal dari beamport reaktor $^{[2]}$. Teknik PGNAA sangat baik digunakan untuk pengukuran unsur-unsur yang memiliki tampang lintang absorbsi neutron yang tinggi seperti $\mathrm{B}, \mathrm{Cd}, \mathrm{Sm}$, dan $\mathrm{Gd}$, unsur-unsur yang terlalu cepat meluruh jika diukur dengan teknik AAN, unsurunsur yang hanya memproduksi isotop stabil, atau unsur-unsur dengan intensitas peluruhan gamma rendah $[2,3]$.

Konsep dasar PGNAA adalah reaksi tangkapan neutron termal yang berasal dari interaksi antara neutron dengan inti/materi. Ketika neutron berinteraksi dengan inti melalui tumbukan tidak elastis, maka selanjutnya akan terjadi penyerapan neutron termal oleh inti sehingga menyebabkan inti mengalami eksitasi dan menyebabkan inti materi bersifat radioaktif. Untuk mencapai keadaan yang stabil, inti selanjutnya akan memancarkan sinar gamma dengan energi yang spesifik (gamma serentak).

Gamma serentak adalah suatu radiasi gamma yang dipancarkan secara bersamaan dari suatu radioisotop dengan waktu yang sangat pendek (sekitar $10^{6} \mathrm{~ns}$ ). Energi yang spesifik tersebut dapat digunakan untuk mengidentifikasi atau menganalisis kandungan unsur dalam materi (sampel) tersebut. Pada keadaan yang lain unsur yang telah bersifat radioaktif tersebut masih memancarkan sinar gamma yang lain. Lebih lanjut tentang konsep dasar PGNAA dapat dilihat pada Gambar 1.

Teknik PGNAA mempunyai sensitivitas yang cukup tinggi untuk analisis unsur-unsur. Beberapa paramater yang dapat mempengaruhi sensitivitas dari teknik PGNAA antara lain :

1. Faktor iradiasi (fluks neutron, iradiasi, dan waktu peluruhan).

2. Kondisi pengukuran (waktu pengukuran dan efisiensi detektor).

3. Unsur radioaktif (kelimpahan isotop, tampang lintang neutron, waktu paruh, dan kelimpahan energi sinar gamma).

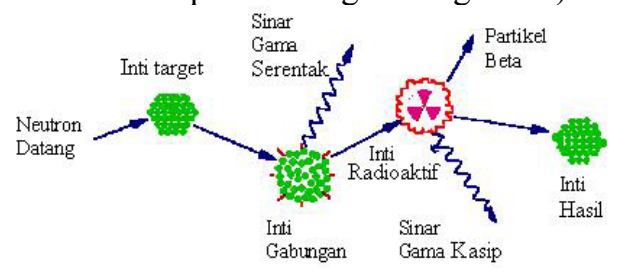

Gambar 1. Diagram proses tangkapan neutron oleh inti yang diikuti dengan emisi gamma ${ }^{[3]}$

\section{Perangkat Spektrometer Gamma}

Perangkat spektrometer gamma yang modern biasanya dilengkapi dengan unit pengolahan data berupa mikrokomputer seperti tampak pada Gambar 2. Detektor yang dipakai dalam spektrometri gamma adalah detektor sintilator $\mathrm{NaI}(\mathrm{TI})$ dan detektor semi-konduktor Germanium kemurnian tinggi (HPGe) atau $\mathrm{Ge}(\mathrm{Li})$.

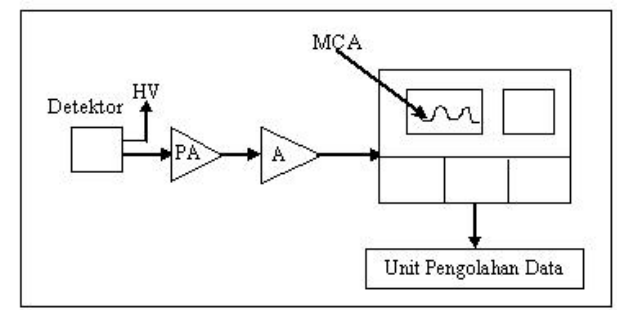

Gambar 2. Diagram Skematik Susunan Perangkat Spektrometer Sinar Gamma

Detektor sintilator $\mathrm{NaI}(\mathrm{Tl})$ adalah detektor yang terbuat dari kristal tunggal natrium iodida yang telah "dikotori" dengan sedikit tallium. Prinsip detektor jenis ini adalah 
foton kelipan hasil interaksi sinar gamma dengan kristal sintilator diubah menjadi signal pulsa oleh tabung pelipat ganda elektron.

Detektor semi-konduktor dapat dipandang sebagai detektor kamar ionisasi di mana medium gas diganti dengan zat padat yang bersifat semi-konduktor. Dalam bahan semi-konduktor, kesenjangan tenaga antara pita valensi dan pita penghantar adalah sekitar $1 \mathrm{eV}$, sedangkan nisbah elektron bebas dalam pita penghantar dan pita valensi sekitar $2 \times 10^{-7}$. Detektor semi konduktor yang dipakai dalam penelitian ini adalah detektor HPGe. Detektor HPGe (High-Purity Germanium detector) tergolong dalam detektor semi-konduktor germanium intrinsik yang berbentuk planar. Tidak seperti detektor $\mathrm{Ge}(\mathrm{Li})$ yang memerlukan pendingin khusus untuk menjamin daya pisah detektor tetap baik, detektor ini hanya perlu didinginkan saja apabila dioperasikan. Detektor semi-konduktor HPGe mempunyai daya pisah yang jauh lebih baik daripada detektor sintilator $\mathrm{NaI}(\mathrm{TI})$.

Pulsa yang dikeluarkan oleh penguat dikirim menuju penganalisis tinggi pulsa yaitu penganalisis salur ganda (Multi Channel Analyzer). MCA berfungsi untuk memisahkan pulsa yang berasal dari cuplikan dengan pulsa derau (noise). Begitu juga dapat dibedakan pulsa yang berasal dari tenaga sinar gamma yang lain. Karena pulsa yang dihasilkan oleh detektor adalah hasil pengubahan interaksi zarah radiasi dengan medium detektor, maka berarti jumlah pulsa yang tercacah sama dengan jumlah zarah radiasi yang mengenai detektor. Sedangkan tinggi pulsa sebanding dengan energi zarah radiasi. MCA dilengkapi dengan rangkaian pengala (timer) yang berfungsi untuk menentukan selang waktu pencacahan pulsa.

Dalam spektrometri, tidak hanya cacah zarah radiasi secara keseluruhan yang perlu diketahui, tetapi juga cacah zarah radiasi pada energi tertentu. Untuk keperluan itu,
MCA dilengkapi pula dengan rangkaian pemilih tinggi pulsa (diskriminator) yang berarti juga pemilih besar energi radiasi yang akan dicacah, karena tinggi pulsa sebanding dengan energi radiasi.

\section{TATA KERJA}

\section{Bahan dan Alat Penelitian}

Bahan dan alat yang digunakan dalam penelitian ini adalah sebagai berikut :

1. Sumber neutron $\mathrm{Pu}-\mathrm{Be}^{239}$

2. Sumber gamma standar $\mathrm{Co}^{60}$ dan $\mathrm{Cs}^{137}$

3. Foil $\mathrm{Ag}^{108}$ dan Foil $\mathrm{Au}^{198}$

4. Nitrogen cair

5. Transfer cask

6. Spektrometer gamma

7. Balok beton

8. Meja tempat sampel

9. Kolimator neutron terbuat dari grafit

\section{Prosedur Penelitian}

Susunan peralatan sistem analisis unsur-unsur dengan metode analisis aktivasi neutron gamma serentak (PGNAA) seperti terlihat pada Gambar 3.

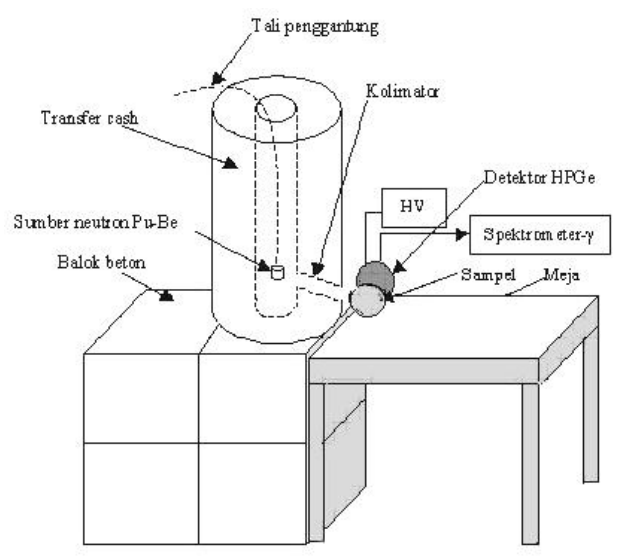

Gambar 3. Konfigurasi Sistem PGNAA

Detektor HPGe dengan ketinggian 710 mm dipasang pada posisi optimum yaitu pada fluks neutron rendah $\left( \pm\right.$ sudut $90^{\circ}$ dari arah sumber neutron). Kolimator yang dipakai untuk mengarahkan pancaran neutron 
mempunyai panjang $220 \mathrm{~mm}$. Sedangkan diameter kolimator $15 \mathrm{~mm}$. Pada permukaan bagian dalam kolimator dipasang pelapis yang terbuat dari bahan plastik. Jarak sampel dengan detektor $5 \mathrm{~cm}$. Transfer cask terbuat dari material beton dengan ketingggian $750 \mathrm{~mm}$ dan diameter lubangnya $155 \mathrm{~mm}$.

\section{Kalibrasi Spektrometer Gamma}

Perangkat spektrometer gamma sebelum digunakan dalam analisis terlebih dahulu dikalibrasi secara cermat dan teliti. Hal tersebut dikarenakan spektrometer gamma merupakan suatu metode pengukuran yang bersifat nisbi ${ }^{[4]}$. Saat melakukan kalibrasi semua fungsi peralatan harus diatur (set) pada kondisi kerja optimum. Fungsi-fungsi tersebut antara lain adalah pengaturan pulsa-zero, DC offset, shaping time, tegangan tinggi (HV) dan lain-lain.

Prosedur yang dilakukan adalah sebagai berikut :

1. Detektor HPGe diisi terlebih dahulu dengan nitrogen cair selama 24 jam.

2. Perangkat spektrometer gamma disusun seperti Gambar 2 dan 3.

3. Tegangan operasi detektor diatur dan disesuaikan.

4. Detektor HPGe diletakkan di depan sumber standar $\mathrm{Co}^{60}$ dan $\mathrm{Cs}^{137}$ pada jarak $5 \mathrm{~cm}$.

5. Pencacahan dilakukan selama 5 menit, data hasil pencacahan disimpan dalam file komputer guna keperluan analisis.

\section{Pengukuran Fluks Neutron}

Radiasi neutron dapat dideteksi dengan dua metode, yaitu langsung dan tidak langsung $[4,5,6]$. Metode langsung adalah suatu metode mendeteksi neutron dengan detektor neutron $\mathrm{BF}_{3}$, Fission Chamber (FC), dan Compensated Ionization Chamber (CIC), atau detektor neutron lainnya di mana keluarannya berupa signal yang sebanding dengan besar intensitas neutron yang diukur. Metode tidak langsung adalah suatu cara mendeteksi neutron dengan cara mengukur aktivitas dari suatu bahan detektor setelah diaktivasi dalam suatu medan neutron. Langkah-langkah yang dilakukan adalah sbb.: menyusun peralatan seperti pada Gambar 2 dan Gambar 3, mengaktivasi foil $\mathrm{Au}^{198}$ selama 24 jam pada posisi yang akan diukur fluks neutronnya, mencacah foil $\mathrm{Au}^{198}$ yang telah teraktivasi dengan spektrometri gamma (detektor HPGe).

\section{Pengukuran Cacah Latar}

Pengukuran cacah latar dilakukan dengan kondisi adanya sumber neutron dan tanpa sumber neutron di dalam kontainer. Susunan peralatan seperti Gambar 3 dan 4, dengan menghilangkan sumber neutron dan sampel. Sistem cacah/spektrometer gamma dioperasikan pada kondisi kerja optimum. Kemudian dilakukan deteksi radionuklida yang berasal dari alam di sekeliling peralatan dengan detektor HPGe dan dicacah selama 5 menit. Spektrum gamma hasil cacahan disimpan dalam file komputer guna keperluan analisis lebih lanjut.

\section{HASIL DAN PEMBAHASAN}

Dengan konfigurasi peralatan eksperimen seperti yang dilukiskan pada Gambar 2 dan 3, dilakukan pengujian dan kalibrasi efisiensi serta resolusi dari sistem PGNAA tersebut. Data kalibrasi energi dan efisiensi disajikan pada Tabel 1, dan data resolusi puncak-puncak gamma dari sistem PGNAA disajikan pada Tabel 2. Ada 2 macam kalibrasi yang perlu dilakukan yaitu kalibrasi energi dan kalibrasi efisiensi. Efisiensi yang ditentukan adalah efisiensi mutlak dari sitem yang dinyatakan sebagai

$$
g(E)=\frac{C P S}{D P S \times Y(E)}
$$

di mana $\varepsilon(E)$ adalah efisiensi mutlak pada energi E, CPS adalah cacah pulsa yang dihasilkan detektor per sekon, DPS adalah disintegrasi atau cacah sinar gamma yang 
dipancarkan sumber per sekon, dan Y(E) adalah intensitas mutlak sinar gamma (yield).

Kalibrasi energi dilakukan untuk tujuan analisis kualitatif unsur. Energi sinar gamma yang mengenai detektor sebanding dengan tinggi pulsa yang dihasilkan oleh detektor dan penguat. Cacah pulsa-pulsa yang mempunyai tinggi sama dicatat dalam suatu salur dengan nomor tertentu. Dengan demikian, nomor salur juga sebanding dengan energi sinar gamma.

Tabel 1 menunjukkan data kalibrasi energi sinar gamma $\mathrm{Cs}^{137}$ dan $\mathrm{Co}^{60}$. Dari data yang dihasilkan jika dicocokkan dengan tabel radionuklida, telah mengalami pergeseran energi rata-rata sebesar 2,703 $\mathrm{keV}$. Adanya pergeseran energi tersebut dimungkinkan karena pengaruh tingginya suhu dan cacah latar. Suhu dalam ruangan reaktor berkisar antara $32-34{ }^{0} \mathrm{C}$ dimungkinkan berpengaruh terhadap sistem elektronik spektrometer gamma. Sistem elektronik tersebut lebih spesifik adalah sistem penguat pulsa (amplifier) yang didalamnya terdapat komponen IC dan transistor. Kedua komponen ini sangat sensitif terhadap suhu yang tinggi sehingga dapat menggeser pulsa-pulsa yang ditangkap oleh detektor.

Faktor kedua yang mempengaruhi pergeseran energi adalah tingginya cacah latar. Cacah latar yang tinggi dimungkinkan karena kekurangsempurnaan sistem perisai dan kolimator neutron, sehingga kebolehjadian tercacahnya partikel radioaktif hasil aktivasi neutron terhambur oleh detektor lebih besar. Akibatnya energi sinar gamma dari sumber standar $\mathrm{Cs}^{137}$ dan $\mathrm{Co}^{60}$ yang seharusnya diperoleh sebesar 661, 1173, dan 1332 (dalam keV) hanya diperoleh sebesar 658, 1170, dan 1329 (keV). Namun hal ini masih dalam batas toleransi mengingat pergeseran energi tersebut berlangsung secara beraturan.

Kalibrasi efisiensi bertujuan untuk mendapatkan harga perbandingan antara laju cacah yang diterima detektor dengan aktivitas sumber standar pada saat dilakukan pencacahan. Seperti yang ditunjukkan pada Tabel 1 yaitu data kalibrasi efisiensi maka dapat dibuat kurva kalibrasi efisiensi. Berdasar data tersebut, setelah dilakukan perhitungan didapatkan harga efisiensi detektor sebesar 0,00657. Hal ini berarti bahwa perbandingan cacah pulsa yang diberikan detektor terhadap aktivitas mutlak sumber gamma adalah $0,657 \%$. Nilai efisiensi ini untuk selanjutnya digunakan dalam analisis kuantitatif unsur.

Tabel 2 menunjukkan data resolusi detektor HPGe, dari tabel tersebut tampak adanya hubungan linier antara resolusi detektor dengan besarnya energi sinar gamma dan lebar tengah puncak kanal (FWHM). Semakin besar energi sinar gamma yang mengenai detektor maka diperoleh resolusi yang semakin kecil. Hal ini berarti kemampuan detektor HPGe untuk memisahkan dua puncak energi sinar gamma yang berdekatan semakin baik seiring dengan makin kecilnya nilai resolusi. Jika masing-masing nilai resolusi tersebut dirata-rata, maka diperoleh nilai resolusi rata-rata sebesar 5,58\%.

Pengujian terhadap sistem analisis unsur-unsur dengan metode aktivasi neutron gamma serentak (PGNAA) dapat dilakukan setelah didapatkan kalibrasi yang baik secara berulang-ulang. Hal penting yang harus dilakukan dalam pengujian yaitu mengetahui besarnya fluks neutron yang terhambur. Ada dua metode untuk mengukur besarnya fluks neutron yaitu metode langsung dan tidak langsung. Metode langsung adalah suatu metode mendeteksi/mengukur neutron dengan detektor $\mathrm{BF}_{3}$, Fission Chamber (FC), dan Compensated Ionization Chamber (CIC). Metode tidak langsung adalah suatu metode mendeteksi neutron dengan cara mengukur aktivitas dari suatu bahan setelah diaktivasi dalam suatu medan neutron. Pada penelitian ini fluks neutron diukur dengan metode 
tidak langsung atau lebih dikenal dengan metode aktivasi.

Fluks neutron rata-rata yang diperoleh pada posisi target dari sistem PGNAA ini adalah $3,26 \times 10^{4} \mathrm{n} / \mathrm{cm}^{2} \mathrm{~s}$. Hasil tersebut (fluks neutron dalam orde $10^{4} \mathrm{n} / \mathrm{cm}^{2} \mathrm{~s}$ ) sesuai dengan referensi yang ada bahwa sumber neutron $\mathrm{Pu}-\mathrm{Be}^{239}$ yang dipakai memiliki kuat sumber $\mathrm{Q} \approx 10^{9} \mathrm{n} / \mathrm{s}$, di mana secara teoritis fluks neutron pada jarak 30 $\mathrm{cm}$ dapat dihitung dengan persamaan :

$$
\phi=\frac{Q}{4 \pi R^{2}}
$$

di mana $\mathrm{Q}$ dan $\mathrm{R}$ masing-masing adalah kuat sumber neutron dan jarak cuplikan dari sumber neutron. Berdasar persamaan di atas, untuk harga $\mathrm{Q} \approx 10^{9} \mathrm{n} / \mathrm{s}$ maka harga fluks neutron disuatu titik pada jarak $30 \mathrm{~cm}$ adalah $8,84 \cdot 10^{4} \mathrm{n} / \mathrm{cm}^{2} \mathrm{~s}$.

Dalam metode pengaktifan neutron gamma serentak (PGNAA), sampel dan detektor berada dalam medan neutron sehingga diperoleh hasil cacah latar yang tinggi. Hal ini bisa terjadi karena perisai radiasi yang terdiri atas susunan balok beton, timbal, dan grafit tidak dapat menyerap secara sempurna seluruh neutron. Akibatnya masih ada neutron yang lolos dari perisai, dan neutron yang lolos ini kemudian menumbuk molekul-molekul udara yang disertai dengan pemancaran foton gamma. Foton-foton gamma yang berasal dari udara ini kemudian ikut tercacah oleh detektor HPGe sehingga menimbulkan cacah latar yang tinggi.

Tabel 1. Data kalibrasi energi dan efisiensi

\begin{tabular}{|c|c|c|c|c|c|}
\hline Sumber & $\begin{array}{c}\text { No. } \\
\text { Salur }\end{array}$ & $\begin{array}{c}\text { Energi } \\
\text { (keV) }\end{array}$ & CPS & Yield & Efisiensi \\
\hline Cs-137 & 645,36 & 658,61 & 75,81 & 1 & 0,0028 \\
Co-60 & 973,04 & 1170,65 & 25,02 & 0,999 & 0,0091 \\
Co-60 & 1176,74 & 1329,73 & 21,57 & 0,997 & 0,0076 \\
\hline
\end{tabular}

Tabel 2. Data resolusi detektor HPGe

\begin{tabular}{|c|c|c|}
\hline Energi (keV) & FWHM & Resolusi (\%) \\
\hline 658,61 & 39,20 & 5,95 \\
1170,65 & 63,51 & 5,43 \\
1329,73 & 71,13 & 5,35 \\
\hline
\end{tabular}

Hasil uji coba untuk pengukuran unsur Ag-108 pada suatu cuplikan, diperoleh harga CPS rata-rata sebesar 2,38 cacah per-sekon, dengan menggunakan relasi persamaan :

$$
m=\frac{C P S A}{k N_{A} \sigma_{a} \phi}
$$

dimana $\mathrm{m}$ : massa unsur, CPS : cacah pulsa yang dihasilkan detektor per sekon, A : nomor massa atom, $\mathrm{k}$ : efisiensi sistem deteksi, NA : bilangan Avogadro, $\sigma_{\mathrm{a}}$ : tampang lintang serapan dari target, dan $\Phi$ : fluks neutron. Diperoleh hasil pengukuran rerata berat cuplikan sunsur Ag-108 sebesar 0,0316 gram

\section{KESIMPULAN DAN SARAN}

Berdasarkan hasil eksperimen dalam penelitian ini dapat disimpulkan bahwa :

1. Telah berhasil dibuat susunan lengkap sistem analisis unsur-unsur dengan metode aktivasi neutron gamma serentak (PGNAA) menggunakan sumber neutron isotopik $\mathrm{Pu}-\mathrm{Be}$, dan diperoleh resolusi detektor sebesar 5,58\%.

2. Kalibrasi dilakukan dengan menggunakan sumber standar $\mathrm{Co}^{60}$ dan $\mathrm{Cs}^{137}$ diperoleh efisiensi sistem deteksi sebesar $0,657 \%$. Pengukuran fluks neutron pada lokasi target (cuplikan) dilakukan dengan menggunakan foil emas $\left(\mathrm{Au}^{198}\right)$, diperoleh fluks neutron rerata sebesar $3,26 \times 10^{4} \mathrm{n} / \mathrm{cm}^{2} \mathrm{~s}$. Fluks sebesar ini sesuai dengan kuat sumber neutron PuBe yang digunakan.

\section{Saran}

Berdasarkan pengalaman dalam pelaksanaan eksperimen dan hasil yang diperoleh pada penelitian ini, maka disarankan : perlu adanya penelitian lanjutan tentang sistem analisis unsur-unsur dengan metode PGNAA ini, menggunakan sistem perisai dan kolimator neutron yang lebih baik. Demikian pula perlu dikembangkan 
dengan menggunakan sumber neutron yang berbeda a.l. sumber neutron dari salah satu beam-port reaktor Kartini, dan membuat kolimator neutron yang baik serta perisai (shielding) yang mampu memperkecil radiasi neutron sehingga tidak mengganggu proses pengukuran. Dengan kata lain perlu adanya penelitian dan pengembangan lebih lanjut sedemikian rupa sehingga sistem PGNAA dapat direalisasikan sebagai salah satu fasilitas untuk layanan analisis unsurunsur.

\section{DAFTAR PUSTAKA}

1. Kruger $P, 1971$. "Principle of Activation Analysis". John Wlley and Sons, New York.

2. Glascock MD, 2002. "An Overview of Neutron Activation Analysis". Missouri University Research Reactor.

3. Sustetyo W, 1988. "Spektrometri Gamma”. Gadjah Mada University Press. Yogyakarta.

4. Knoll GF, 1971. "Radiation Detection and Measurement". John Wlley and Sons. New York.

5. IAEA-TECDOC-1234, 2001. "The Applications of Research Reactors". IAEA. Vienna.

6. IAEA-TECDOC-1215, 2001. "Use of Research Reactors for Neutron Activation Analysis”. IAEA. Vienna. 